\title{
Review
}

Journal of Innate

Immunity
J Innate Immun 2011;3:344-354

DOI: $\underline{10.1159 / 000327014}$
Received: November 9, 2010

Accepted after revision: February 18, 2011

Published online: May 11, 2011

\section{Mechanisms of Tumor and Viral Immune Escape from Natural Killer Cell-Mediated Surveillance}

\author{
Ariane Groth $^{\mathrm{a}}$ Stephan Klöss ${ }^{\mathrm{b}} \quad$ Elke Pogge von Strandmann ${ }^{\mathrm{c}} \quad$ Ulrike Koehl ${ }^{\mathrm{b}}$ \\ Joachim Koch ${ }^{\mathrm{a}}$ \\ anstitute of Biomedical Research, Georg-Speyer-Haus and ${ }^{b}$ Laboratory for Stem Cell Transplantation and \\ Immunotherapy, Hospital of the Johann Wolfgang Goethe University, Paediatric Haematology and Oncology, \\ Frankfurt am Main, and CInternal Medicine, Hospital of the University of Cologne, Cologne, Germany
}

\section{Key Words}

Natural killer cells $\cdot$ Immunosurveillance $\cdot$ Tumor immune escape $\cdot$ Viral immune evasion • Natural killer cell therapy • Ligand shedding $\cdot$ NKG2D $\cdot$ Neuroblastoma

\begin{abstract}
Human natural killer (NK) cells recognize and efficiently eliminate $\mathrm{MHC}$ class I low or negative malignant targets and virally infected host cells, without requirement for prior sensitization. However, viruses and various tumor cells display elaborate adaptations to evade and overcome immunosurveillance. The current review focuses on escape mechanisms of viruses and malignantly transformed 'stressed' cells to evade from NK cell cytotoxicity. A general overview of recent clinical studies using allogeneic donor NK cells is given, summarizing first data about a possible benefit for patients suffering from high-risk leukemia and solid tumors. Finally, the review discusses the future perspectives and hypotheses aiming to improve therapeutic NK cell strategies against tumor immune escape mechanisms.
\end{abstract}

Copyright ๑ 2011 S. Karger AG, Basel

A.G. and S.K. contributed equally to this work. U.K. and J.K. share senior authorship.
(C) 2011 S. Karger AG, Basel

$1662-811 X / 11 / 0034-0344 \$ 38.00 / 0$

Fax +4161306 1234

E-Mail karger@karger.ch

www.karger.com
Accessible online at: www.karger.com/jin

\section{Introduction}

Natural killer (NK) cells are important effector cells of the innate immunity against virus-infected and malignantly transformed cells. Recognition and killing of target cells is mediated by a balance of activating and inhibitory signals $[1,2]$. NK cells kill their target cells by the polarized release of cytotoxic granules containing perforin and granzymes [3]. Killing of the target can also be achieved by ligation of the tumor necrosis factor (TNF) receptor family members Fas/CD95, TRAILRs and TNFR1 on tumor cells with their corresponding ligands (FasL, TRAIL and TNF) expressed on, or secreted by, NK cells $[3,4]$. In combination with the adaptive immune response, NK cells are able to lyse targets by antibody-dependent cellular cytotoxicity, which is initiated after binding of the Fc portion of an IgG antibody to its receptor (Fc- $\gamma$ RIII, CD16) on NK cells (fig. 1a).

Activating signals (from receptor ligation of induced cellular ligands or viral proteins) triggers the cytotoxicity of NK cells, whereas predominance of inhibitory signals (from receptor ligation of MHC class I molecules) leads to tolerance $[1-3,5,6]$. The 'missing self' recognition theory describes the phenomenon that malignantly transformed cells, which lack expression of specific MHC class I molecules, trigger NK cell-dependent activation [7, 8].

PD Dr. Joachim Koch

Institute of Biomedical Research, Georg-Speyer-Haus

Paul-Ehrlich-Strasse 42-44

DE-60596 Frankfurt am Main (Germany)

Tel. +49696339 5322, E-Mail joachim.koch@em.uni-frankfurt.de 
By contrast, erythrocytes are not lysed by NK cells although they lack MHC class I molecules on their surface, arguing for the existence of an 'induced self' component in decision making [9]. The majority of mature unstimulated NK cells express at least one receptor specific for self-MHC $[10,11]$, however, several NK cells lack receptors for self-MHC and are hyporesponsive [12-14].

Each NK cell expresses its own repertoire of activating and inhibitory receptors (average 2-9) [15, 16]. Human inhibitory receptors comprise both, killer cell immunoglobulin-like receptors (KIRs), which recognize HLA class I molecules, and the heterodimeric C-type lectin receptor CD94-NKG2A, which binds to HLA-E. The main activating receptors involved in the recognition and killing of malignantly transformed cells include the natural cytotoxicity receptors (NCRs) NKp30, NKp44 and NKp46, whose few ligands identified so far remain poorly characterized on the molecular level, as well as NKG2D, 2B4 and DNAM-1 receptors recognizing a variety of well-defined ligands $[1,2,17,18]$. The importance of these activating receptors is underscored by the fact that the surface density of NCRs is correlated with the degree of NK cell-mediated cytotoxicity towards malignantly transformed cells $[19,20]$.

In the current review, we will focus on the interaction between malignantly transformed cells or virus-infected cells and NK cells as an essential part of the first line of immunosurveillance.

\section{Tumor Escape from NK Cell-Mediated Immunity}

The transformation of a normal cell into a malignant cell, which eventually escapes from immunosurveillance, requires a large number of intrinsic oncogenic events. To date, it is estimated that tumor transformation results from approximately 80 mutations within an individual cell, affecting the functionality of around 6-8 signaling pathways [21]. However, there are numerous intrinsic barriers that inhibit the development of cancer [22, 23]. There are two major challenges for immunosurveillance of malignantly transformed cells: (1) tumor cells originate from 'self' as well as their biochemical properties and their behavior differs only subtly from their healthy counterparts, and (2) tumor cells employ many tricks to actively bypass detection and elimination by effector cells of the immune system (comprehensively reviewed by Vesely et al. [23]).

Cells of the adaptive immune system may detect tumor antigens in the context of MHC class I antigen pre- sentation. In contrast, NK cells kill malignantly transformed cells after interaction of induced or overexpressed ligands with their activating receptors. This killing may occur, provided that MHC-mediated inhibition is lowered by the downregulation of MHC class I molecules from the surface of malignantly transformed cells. Among the ligands of NKG2D, the MHC class I chain-related proteins $\mathrm{A}$ and $\mathrm{B}(\mathrm{MICA} / \mathrm{B})$ and the unique long 16-binding proteins (ULBPs) have been studied in molecular detail. MICA and MICB are highly polymorphic and resemble the MHC class I heavy chain in structural organization, but fail to associate with $\beta 2$-microglobulin and peptide. The ULBPs are either transmembrane or glycosylphosphatidylinositol anchored and comprise only the MHC class I-like $\alpha 1$ and $\alpha 2$-domains [17].

In healthy adult cells, the expression of NKG2D ligands is restricted to the thymic epithelium and to the gastrointestinal mucosa [24]. However, MICA/B and other ligands are upregulated on the surface of many cell types after malignant transformation and under conditions of stress such as heat shock [24], oxidative stress [25], genotoxic stress and stalled DNA replication, which activate a major DNA damage checkpoint controlled by ATM or ATR protein kinases [26]. Ligand overexpression has been detected in solid tumors of multiple origins and in lymphoproliferative malignancies. Some oncogenes may directly upregulate the expression of NKG2D ligands. As an example, the BCR/ABL fusion oncoprotein induces the expression of MICA on leukemia cells in chronic myeloid leukemia, whereas it is absent on healthy donor hematopoietic CD34 ${ }^{+}$stem cells [27]. However, transformation alone has shown to be insufficient to induce NKG2D ligand transcription, since the expression of the oncogenes (K-ras and $c$-myc or Akt and $c$-myc), or the lack of tumor suppressor p53 alone do not induce NKG2D ligand expression on primary ovarian epithelial cells [26].

The regulated expression of ligands of the activating NK cell receptors might have several consequences: (1) upregulation of NK cell ligands might be a cell intrinsic protective mechanism in order to render altered cells susceptible to killing, (2) reduced ligand expression is beneficial to tumor cells in order to prevent NK cell activation, and (3) shedding of ligands might interfere with NK cell activation. A selection of NKG2D-dependent immune evasion strategies employed by malignantly transformed cells is detailed below. 


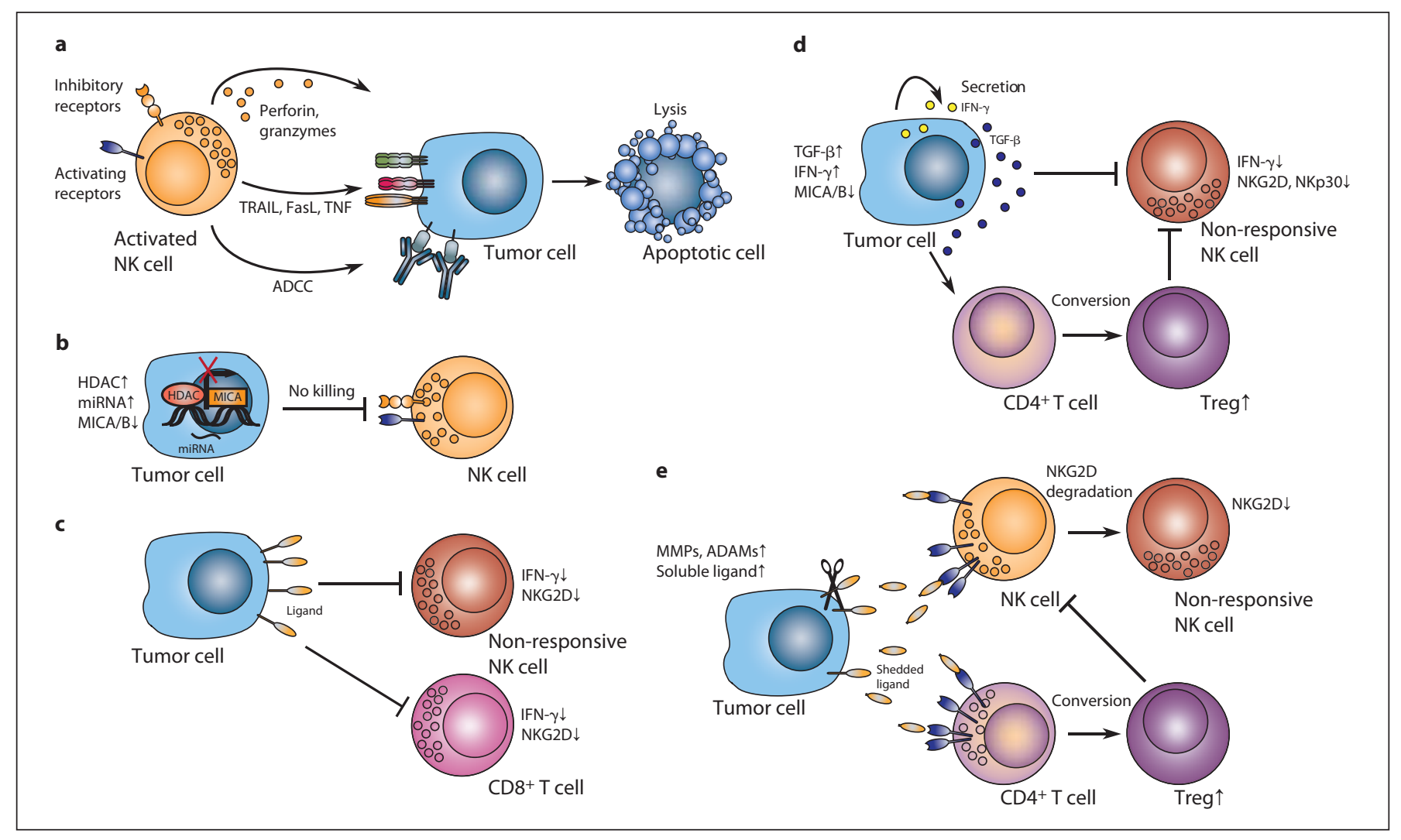

Fig. 1. Strategies of tumor immune escape from NK cell-dependent immunosurveillance. NK cell recognition is mediated by a fine-tuned balance of activating and inhibitory signals. a NK cells kill their target cells by the combined release of cytotoxic granules containing perforin and granzymes, by the expression or release of TRAIL, TNF and FasL and by antibody-dependent cellular cytotoxicity, resulting in apoptosis of the target cell. Tumor cells may escape NK cell dependent immunosurveillance by several pathways: alterations in DNA modifying enzymes such as HDACs or microRNAs, involved in epigenetic gene regulation, repress the expression of MICA/B (b), persistent expression of activating ligands and sustained triggering of NKG2D leads to hypo-respon-

\section{Persistent Expression of NKG2D Ligands}

Persistent NKG2D ligand expression and the sustained triggering of receptor signaling by appropriate cellular ligands lead to profound downregulation of surface NKG2D from NK cells and activated CD8 ${ }^{+} \mathrm{T}$ cells. Consequently, NK cell cytotoxicity is reduced, and aggressiveness of tumor growth is increased in transgenic mice in vivo $[28,29]$ (fig. 1c). Importantly, cytokine stimulation of NK cells, which were chronically exposed to NKG2D ligands in vitro, could restore NKG2D expression [29]. Thus, ex vivo stimulation of NK cells with cytokines might improve immunotherapy (see below). siveness and decreased cytotoxicity due to decreased NKG2D expression and reduced IFN- $\gamma$ production (c), tumor-released cytokines such as TGF- $\beta$ and IFN- $\gamma$ repress MICA/B expression, downmodulate NKG2D expression and IFN- $\gamma$ production in NK cells and promote the conversion of $\mathrm{CD} 4^{+} \mathrm{T}$ cells into regulatory $\mathrm{CD}^{+} \mathrm{CD} 25^{+} \mathrm{FOXP}^{+}{ }^{+} \mathrm{T}$ cells, which suppress immunosurveillance (d) and upregulation of MMPs and ADAMS, which promote the shedding of activating ligands such as MICA, which binds to NKG2D on $\mathrm{CD}^{+} \mathrm{T}$ cells and NK cells, resulting in hyporesponsiveness in NK cells due to degradation of NKG2D and conversion of $\mathrm{CD} 4^{+} \mathrm{T}$ cells into regulatory $\mathrm{CD} 4^{+} \mathrm{CD} 25^{+} \mathrm{FOXP}^{+} \mathrm{T}$ cells $(\mathbf{e})$.

\section{Downregulation of NKG2D Ligands by Cytokines}

Due to their diverse immunomodulatory functions, the individual effects of cytokines on NK cell-dependent immunosurveillance of tumor cells are not precisely determined. Among these, the transforming growth factor$\beta$ (TGF- $\beta$ ), which is upregulated in many cancer types, has been studied intensively. TGF- $\beta$ is one of the key immune regulators in tumor initiation and progression. TGF- $\beta$ functions both as a suppressor and as a promoter of tumor formation, but the underlying molecular mechanisms remain unclear. TGF- $\beta$ downmodulates NKp30 and NKG2D receptor expression, thereby suppressing NK 
cell cytolytic activity (fig. 1d) [30, 31]. As an example, release of TGF- $\beta$ by human glioma cells decreases NKG2D levels in $\mathrm{CD}^{+} \mathrm{T}$ and NK cells and at the same time represses the expression of MICA and ULBP1 [32]. Neutralization of TGF- $\beta$ enhances the antitumor response of NK cells (and CD8 ${ }^{+} \mathrm{T}$ cells) by accumulation of IFN- $\gamma$-producing NK cells with IFN- $\gamma$ preservation of surface NKG2D [33]. Additionally, TGF- $\beta$ plays an important role in the conversion of activated $\mathrm{CD} 4^{+} \mathrm{CD} 25^{+} \mathrm{T}$ cells into regulatory $\mathrm{CD} 4{ }^{+} \mathrm{CD} 25^{+} \mathrm{FOXP}^{+} \mathrm{T}$ cells (Tregs), a subpopulation that is commonly found in high numbers in the tumor microenvironment. Regulatory T cells reduce NKG2D expression and suppress NKG2D-mediated NK cell cytotoxicity, thereby promoting tumor progression [34].

Recently, a role of IFN- $\gamma$ in MICA/B and ULBP expression was demonstrated. In glioma and melanoma, IFN- $\gamma$ was shown to downregulate MICA mRNA and consequently MICA surface levels, suggesting an interesting therapeutic intervention possibility (fig. 1d) [35].

\section{Epigenetic Repression of NKG2D Ligand Expression}

Many cancer types display alterations in epigenetic gene regulation. Histone deacetylases (HDACs), that control the accessibility of chromatin for transcription factors and repress tumorigenesis, are frequently over-expressed in cancer cells [36]. As recently shown, the expression of MICA/B is influenced by HDAC activity, since inhibitors of HDACs have been shown to induce the expression of MICA/B on epithelial and leukemic cells. The observed hypoacetylation of histones within the promoter regions of MICA/B suggests an epigenetic repression of these promoters. Subsequent treatment with HDAC inhibitors markedly increased the expression of MICA/B in these cells, whereas the expression level of $\mathrm{MICA} / \mathrm{B}$ in mononuclear cells from healthy donors was unchanged $[37,38]$. Recently, HDAC3, was identified as a key repressor of ULBP expression in epithelial cancer cells, highlighting HDAC inhibitors as putative tools to restore immunogenicity of certain tumors [39]. Another approach to block MICA/B expression might be the use of microRNAs [40] (fig. 1b).

\section{Ligand Shedding and Downregulation of NKG2D}

Soluble NKG2D ligands were initially detected in sera from patients suffering from different types of cancer. The soluble variants of MICA/B are generated by shed- ding from the surface of tumor cells, diffusing into the tumor periphery and dampening NKG2D-dependent immunosurveillance [41-44]. Due to its high concentrations in patients' sera, soluble MICA is a prognostic marker for cancer at early stages. Moreover, MICB serum levels correlate with disease progression and formation of metastases [43].

The consequences of NKG2D ligand shedding are manifold: (1) the number of ligands on the target cell surface is reduced and, consequently, the number of interaction sites for the NK cell is limited, (2) soluble NKG2D ligands can bind to NKG2D on the NK cell and promote its endocytosis as well as degradation, and (3) shedding of MICA/B stimulates the expansion of regulatory $\mathrm{NKG}_{2} \mathrm{D}^{+} \mathrm{CD} 4^{+} \mathrm{T}$ cells, which play a major role in immune suppression [45].

The proteases which promote shedding of MICA from the plasma membrane of tumor cells are ill defined, however, they are members of the family of matrix metalloproteinases (MMPs) and the ADAM family as shown by inhibition studies with several generic inhibitors (fig. 1e) [42]. MMPs are structurally related endopeptidases which can degrade proteins of the extracellular matrix [46]. Shedding of MICA ligands from the cell surface is regulated by interaction with a chaperone called endoplasmic reticulum protein 5 . Endoplasmic reticulum-resident chaperones are upregulated in many cancer types and translocated to the plasma membrane in response to cellular stress. On the cell surface, endoplasmic reticulum protein 5 mediates the reduction of a disulfide bond in the $\alpha 3$ domain of MICA and a subsequent conformational change that is essential for proteolytic cleavage of MICA and metalloproteinases of the ADAM family [47]. Among these, ADAM10 and ADAM17, which are known to cleave proteins within the membrane-proximal stalk region, were shown to be involved in the shedding of MICA and ULBPs $[48,49]$. The contribution of other metalloproteinases such as ADAM9 and MMP14 has also been reported [50]. MICA/B are highly polymorphic and thus the shedding mechanism employed differs among the different alleles. As an example, full-length $\mathrm{MICA}^{*} 008$ is released from cells on exosomes by an ADAM-independent mechanism [51]. Of note, similar observations have been made for the different ULBPs [52].

Ligand shedding by tumor cells via MMPs is a common immune evasion mechanism that opens up several possibilities for intervention. Many efforts are directed towards inhibition of MMP activity, and several MMP inhibitors are studied in clinical cancer trials. However, the first clinical trials show no statistically significant 
benefit on survival. Moreover, side effects of MMP inhibition were observed since MMPs are involved in ligand shedding but also in other processes, such as tissue morphogenesis, tissue repair and angiogenesis.

\section{Virus-Mediated Immune Escape from NK Cells}

The straightforward strategy to subvert the immune response of NK cells is to infect and destroy the killer itself. Many viruses such as poxviruses, influenza, HIV, EBV and HSV have been reported to interfere directly with NK cell function [53]. Several strategies are pursued: (1) inhibition of NK cell activating receptors, (2) virusinduced expression of cytokine-binding proteins or cytokine receptor antagonists, (3) inhibition of apoptosis, (4) selective down- or upregulation of HLA alleles from the host cell surface, (5) virus-induced expression of MHC I homologues in host cells and (6) infection of NK cells.

\section{Alteration of NK Cell Receptors under the Influence of Viral Infections}

In the context of virus immunosurveillance, the NKG2D receptor and the NCRs play a major role $[54,55]$. There are several other stimulatory NK receptors, yet, their immunological function and signaling pathways are poorly understood [1].

Herpes viruses employ sophisticated mechanisms to reduce the overall level of surface $\mathrm{MHC}$ class I molecules on the host cell to escape from killing by cytotoxic T lymphocytes (CTLs). At the same time they maintain the level of certain HLA alleles, which serve as ligands for inhibitory NK cell receptors to escape from killing by NK cells. Human cytomegalovirus (HCMV), which causes life-threatening infections in immunocompromised individuals such as AIDS patients or organ transplant recipients, employs several tricks to evade recognition. At least 4 HCMV proteins (US2, US3, US6 and US11) promote a drastic reduction in MHC class I antigen presentation to CTLs by interfering with MHC class I processing, leading to escape from immunosurveillance and persistence within the host [56]. In a similar way, the HIV-1 protein Nef and the K3 and K5 proteins of the Karposi's sarcoma-associated herpes virus (KSHV) downregulate the cell surface expression of MHC class I molecules by redirecting them to the endosomal pathway $[55,57]$. Nef decreases HLA-A and HLA-B molecules on the cell surface of HIV-infected cells. Interestingly, the HLA-C and
HLA-E alleles are not affected and are therefore still available for binding to the inhibitory KIR or CD94/ NKG2A receptors. As a result, HIV achieves inhibition of both, CTL- as well as NK cell-mediated killing of the host cell.

Based on the 'missing self hypothesis' [7, 8], the loss of surface MHC class I molecules leads to NK cell-mediated killing of the target cell, which is in accordance with the fact that US2-11 deletion mutants of HCMV conferred resistance to NK cell lysis when compared to wild-type HCMV [58]. In order to circumvent elimination by NK cells, HCMV employs the proteins UL18, UL142 and UL40. UL18 mimics MHC class I molecules and serves as decoy ligand for inhibitory NK cell receptors [59]. UL40 provides a leader peptide, which serves as an efficient ligand for presentation on HLA-E molecules. These peptide::HLA-E complexes bind to the inhibitory NK cell receptor CD94/NKG2A thereby preventing the activation of NK cells [60].

Besides restoration of inhibitory signals, the most common viral evasion strategies interfere with activating receptor functions by downregulation of their corresponding ligands in infected cells. As an example, certain strains of HCMV increase the resistance of their host cells to NK cell killing by downregulation of LFA-3 [61], which interferes with binding of LFA-3 to the NK cellactivating receptor $\mathrm{CD} 2$. Another example is provided by K5 of KSHV. The gene product MIR1, an E3 ubiquitin ligase, inhibits NK cell cytotoxicity by downregulation of the ligands ICAM-1 and B7-2 by ubiquitylation and reduced surface expression of NK cell receptors $[1,62]$.

Another mechanism to avoid NK cell activation is to inhibit binding of activating receptors to its corresponding ligand. A prominent example is the HCMV-encoded protein UL16, which binds to ULBPs and MICB in virusinfected cells leading to retention and sequestration of these ligands as well as inhibition of their interaction with NKG2D [63]. In a similar way, HIV reduces cell surface expression of the ligands MICA, ULBP-1 and ULBP2 via the Nef protein [64]. A second way viruses interfere with activating receptor function is secondary modification of the ligand on the target cell surface. HIV and the human $\mathrm{T}$ cell lymphotrophic virus I or II sialylate cell surface molecules, and although binding is not impaired, the cytotoxicity of NK cells is abrogated [65].

Another strategy by which viruses interfere with activating receptor function is the inhibition of downstream signaling following ligation of activating receptors. In this context, the Tat protein of HIV can block recognition of LFA-1 by activating receptors on the NK cell. Adhesion 
to the target cell is not affected, but an L-type calcium channel is bound. The binding blocks calcium influx and subsequently the induction of the calcium-calmodulin kinase II in NK cells required for cytotoxicity [66]. Recently, the HCMV tegument protein pp65, one of the dominant antigens for HCMV-specific CTL responses [67], has been found to block NK cell cytotoxicity through interactions with NKp30 [68]. The authors propose that binding of pp65 results in dissociation of NKp30 and the $\mathrm{CD} 3 \zeta$ chain, which is required for immunoreceptor tyrosine-based activation motif-dependent signaling. However, it remains unclear how viral pp65 and cell surface NKp30 on the NK cell interact.

Beside viral proteins, also virus-derived noncoding regulatory RNAs, such as microRNAs are effectors in immune evasion strategies. As an example, HCMV-derived miR-UL112 can prevent translation of MICB. A similar observation was made for other viruses such as KSHV and EBV [69].

\section{Modulation of Cytokines and Chemokines}

Cytokines play a key role in the initiation and regulation of the innate and adaptive immune responses. In this context, viruses interfere with NK cell responses through virus-encoded proteins that counteract or modulate the interactions between cytokine or chemokine molecules and their corresponding receptors. These pathways are not exclusive to NK cells, and are therefore not strictly separated. Many viruses block signal transduction by ligands of the TNF family, whereas others induce cytokine pathways such as the EBV latent membrane protein 1 that recruits components of the TNF receptor and CD40 transduction machinery to mimic a cytokine response that could be beneficial to the virus. A fascinating mechanism is the mimicry of cytokines (virokines) and cytokine receptors (viroceptors) by large DNA viruses such as herpes viruses and poxviruses [70]. The functions of these viral homologues are diverse. Soluble viral receptors neutralize cytokine activity and viral cytokines might antagonize cytokines such as IL-12, IL-18, TNF- $\alpha$, IL- $1 \alpha$, IL-1 $\beta$ and IL-15, which participate in the stimulation of IFN- $\gamma$ production and cytotoxicity by NK cells. Alternatively, viruses facilitate overproduction or encode homologues of cytokines such as IL-10 that have an inhibitory effect on NK cells. Viral chemokines, including MIP- $1 \alpha$, MIP-1 $\beta$, MCP-1, MCP-2, MCP-3 and RANTES, can affect NK cell chemotaxis. Moreover, chemokines can affect the recruitment of other immune cells [71].

Immune Escape from NK Cells
KSHV encodes for the broad-spectrum chemokine (including CC, CXC and CX3C) antagonist vMIP-II, which can block chemotaxis of monocytes to RANTES, MIP- $1 \alpha$ and MIP- $1 \beta$. In addition, vMIP-I binds to receptors on NK cells [72]. Moreover, HCMV and EBV possess IL-10 homologues, which have been found to inhibit the production of type 1 cytokines and to act directly on NK cells [73]. Specific interference with NK cell activation can also be mediated by cytokine-binding protein homologues. A principal target is IL-18, which is central in NK cell production of IFN- $\gamma$. Ectromelia poxvirus encodes a cytokine-binding protein, which is homologous to IL$18 \mathrm{BP}$ and inhibits IL-18 receptor binding as well as activity [74].

\section{Inhibitors of Apoptosis}

NK cells eliminate virus-infected cells by inducing apoptosis via secretion of cytokines such as TNF, the release of perforin and granzymes, or the ligation of Fas on the target cell. In order to prevent induction of apoptosis, viral proteins inhibit the activation of caspases and encode homologues of antiapoptotic proteins such as Bcl-2 or FLIP. Apoptotic signals triggered by the TNFR family members are blocked by death effector domain-containing proteins, which inactivate IFN-induced PKR and the tumor suppressor p53 [71].

These mechanisms developed by viruses highlight the importance of NK cells in defense against viral infection. Further studies of viral evasion strategies will provide insights into NK cell biology as well as potential therapeutic targets to support immune response.

\section{Prospects for the Use of NK Cells in Immunotherapy Trials of Cancer}

Various studies have revealed that NK cells are particularly efficient in the eradication of metastasizing tumor cells and small tumors, but fail to eliminate larger tumors [75]. Rosenberg et al. [81] pioneered NK cellbased immunotherapy by administration of autologous IL-2-activated killer cells to patients with advanced cancer. Although the authors could clearly demonstrate antitumor effects against different kinds of solid tumors in some of their patients, it is known that the cytotoxic potential of autologous NK cells is weak compared to allogeneic NK cells. Based on the fact that allogeneic, in particular haploidentical, NK cells can target human malig-

J Innate Immun 2011;3:344-354 
nancies in a superior way, new protocols for allogeneic NK cell-mediated immunotherapy are being developed. In these trials, NK cell function could be improved by cytokine stimulation, especially treatment with IL-2, leading to an enhanced NK-cell cytotoxicity and enhanced antitumor response [20,76]. There is good evidence that a combination of cytokines like IFN- $\alpha$, IL-2, IL-12, IL-15, IL-18 and IL-21 may further increase the cytotoxic activity of NK cells [77] and possibly modify the NK cell receptor repertoire. In addition to antitumor response, a multitude of potentially beneficial effects, such as NK cells versus leukemia activity, NK cells versus residual host $\mathrm{T}$ cell activity and NK cells versus host dendritic cell activity with a reduced risk of graft-versushost disease (GvHD), was observed by allogeneic NK cells in vivo [78].

Furthermore, drugs widely used in supportive care, such as ketamine, thiopental and morphine, suppress NK activity and increase the risk for pulmonary metastasis in rats [79]. This deleterious effect could be prevented by small doses of immunostimulators and underline the importance of a sufficient NK activity in anticancer immunity. A comprehensive overview of the prospects for the use of NK cells in immunotherapy of human cancer is given by Ljunggren et al. [80].

\section{NK Cell-Based Immunotherapy of Solid Tumors and Leukemia}

Cell therapy provides a promising treatment option for patients suffering from leukemia and solid tumors that harbor a high risk for relapse after allogeneic, especially haploidentical stem cell transplantation (SCT). Whereas the established $\mathrm{T}$ cell therapies (donor lymphocyte infusions) are known to cause GvHD, NK cells may mediate graft-versus-leukemia/tumor effects without induction of GvHD. Therefore, immunotherapy with highly purified NK cells in recipients of haploidentical SCT could serve as an attractive alternative cell therapy $[82,83]$.

After SCT, the stem cells of the donor reconstitute the immune cells and finally a new immune system in the patient. Although recovery time and velocity vary among patients, NK cells are the first population of developing lymphoid cells after SCT [84]. Due to their early reconstitution, NK cells might play a pivotal role in the lysis of malignantly transformed cells in patients. However, the early expansion phase after SCT is characterized by an unusually high percentage of immune-regulatory CD56 ${ }^{\text {bright }} \mathrm{NK}$ cells, which gradually decline but persist for at least 1 year [85]. Another study demonstrated that early reconstituting NK cells are immature and display impaired cytotoxicity [86], thus illustrating the necessity for additional donor NK cell-based immunotherapy to enhance graft-versus-leukemia/tumor effects.

Enriched NK cells can be infused without additional manipulation, after overnight culture in high-dose IL-2 or after expansion with IL-2 for two weeks [87-91]. First clinical trials show the feasibility of freshly purified or IL-2-activated donor NK cells for the treatment of highrisk patients suffering from leukemia or tumors in both nontransplant settings and after haploidentical SCT as an additional immunotherapy $[88,90,92,93]$. NK cells were applied in a single dose or several times with doses between $0.2 \times 10^{7}$ and $8.1 \times 10^{7} \mathrm{CD}^{2} 6^{+} \mathrm{CD}^{-} \mathrm{NK}$ cells $/ \mathrm{kg}$ body weight with less than $2.5 \times 10^{4} \mathrm{CD}^{+} \mathrm{T}$ cells $/ \mathrm{kg}$ body weight $[20,83,93]$. NK cells were well tolerated by the patients without development of GvHD above grade II. However, a few cases of GvHD have been observed after NK cell infusion which might be partly associated with insufficient $\mathrm{T}$ cell depletion during cell preparation. In a pioneer study, it was demonstrated that patients with AML had a reduced rate of leukemia relapse, a lower rate of graft rejection and a paradoxical reduction in GvHD after haploidentical SCT if the NK cells possessed inhibitory KIRs for which the recipient had no ligand [78]. Recently, Rubnitz et al. [93] have described that NK cell application led to a 2-year event-free survival of all patients in a cohort of 10 pediatric patients with AML in first complete remission.

In solid cancers, the use of NK cells for immunotherapy is rare. We observed an increased cytotoxic activity of activated NK cells against high-risk neuroblastoma (NB) due to IL-2 mediated upregulation of the activating receptors NKp30, NKp44, NKp46 and NKG2D [20].

Taken together, these first clinical data show that the application of ex vivo purified donor NK cells with or without further IL-2 stimulation is feasible, well tolerated and holds a great potential for immunotherapy of patients suffering from various malignancies without severe side effects.

\section{Escape from NKG2D-Dependent Immunosurveillance after Allogenic NK Cell Transplantation in Neuroblastoma}

In an ongoing clinical phase I/II NK cell study, we treat patients suffering from high-risk NB with allogeneic IL-2 stimulated donor NK cells after haploidentical 
SCT in order to improve the clinical outcome [44]. Although NB cells frequently overexpress NKG2D ligands on their surface, growth of these malignantly transformed cells becomes progressive due to various tumor escape mechanisms [94]. In our study, we monitored the levels of soluble MICA in NB patients' plasma prior to and at several time points after NK cell application together with the expression level of NKG2D on donor NK cells. Elevated levels of tumor-released MICA in patients' plasma correlated significantly with impaired NK cell cytotoxicity and highlight the influence of shed ligand on tumor immune escape leading to impaired NKG2D-dependent cytotoxicity of ex vivo stimulated donor NK cells in vivo. Most importantly, this effect could be temporarily reversed by infusion of large numbers of activated NK cells expressing high NKG2D levels, which were able to scavenge shed MICA and retained cytotoxicity via nonoccupied NKG2D receptors [44].

\section{Future Perspectives}

Future studies should improve NK cell immunotherapy by (1) increasing the cytotoxicity of NK cells against various malignancies, (2) optimizing the schedule of the NK cells and (3) developing strategies to overcome tumor immune escape mechanisms. Given the plausible benefit of IL-2-stimulated NK cells compared to freshly isolated, resting NK cells with regard to cytotoxicity, additional increase in cytotoxicity may be achieved by activation with cytokine combinations like IL-2/IL-15 or by cross- talk with dendritic cells. In order to overcome immune escape, treatment options are: (1) monoclonal antibodies against soluble MICA, (2) genetically engineered NK cells with chimeric receptors for tumor targeting and improved recognition of tumor cells or (3) using small interfering RNA to downregulate inhibitory receptors. Open issues in clinical studies include the optimal number of infused NK cells, the injection scheme, the appropriate selection of donor/recipients and the type of disease, since certain types of malignantly transformed cells are more susceptible to NK cell therapy than others. Taken together, cellular immunotherapy of cancer is a very recent concept and only starts to provide evidence of selectivity, applicability and safety. The efficacy of cell therapy still has to be demonstrated but will probably emerge as a complementary strategy for actual therapies. Finally, combinatorial approaches using drugs, antibodies, cytokines and cells may become successful attempts limiting immune escape from tumors.

\section{Acknowledgements}

The Georg-Speyer-Haus is supported by the Bundesministerium für Gesundheit and the Hessisches Ministerium für Wissenschaft und Kunst. The Laboratory for Stem Cell Transplantation and Immunotherapy is promoted by the Frankfurter Stiftung für krebskranke Kinder, the Bundesministerium für Bildung und Forschung (project-executing organization: Deutsches Zentrum für Luft- und Raumfahrt), the Adolf Messer-Stiftung and the Alfred und Angelika Gutermuth-Stiftung. We thank Prof. Dr. Alexander Steinle and Dr. Cyril Fauriat for helpful discussions and critical reading of the manuscript.

\section{References}

1 Lanier LL: NK cell recognition. Annu Rev Immunol 2005;23:225-274.

- Vivier E, Tomasello E, Baratin M, Walzer T, Ugolini S: Functions of natural killer cells. Nat Immunol 2008;9:503-510.

-3 Farag SS, Caligiuri MA: Human natural killer cell development and biology. Blood Rev 2006;20:123-137.

-4 Moretta L, Bottino C, Pende D, Castriconi R, Mingari MC, Moretta A: Surface NK receptors and their ligands on tumor cells. Semin Immunol 2006;18:151-158.

5 Moretta L, Bottino C, Cantoni C, Mingari MC, Moretta A: Human natural killer cell function and receptors. Curr Opin Pharmacol 2001;1:387-391.

6 Parham P: Influence of KIR diversity on human immunity. Adv Exp Med Biol 2005;560: $47-50$.
7 Ljunggren HG, Karre K: In search of the 'missing self': MHC molecules and NK cell recognition. Immunol Today 1990;11:237244.

8 Karre K: Natural killer cell recognition of missing self. Nat Immunol 2008;9:477-480.

-9 Li Q, Dong C, Deng A, Katsumata M, Nakadai A, Kawada T, Okada S, Clayberger C, Krensky AM: Hemolysis of erythrocytes by granulysin-derived peptides but not by granulysin. Antimicrob Agents Chemother 2005;49:388-397.

10 Fernandez NC, Treiner E, Vance RE, Jamieson AM, Lemieux S, Raulet DH: A subset of natural killer cells achieves self-tolerance without expressing inhibitory receptors specific for self-MHC molecules. Blood 2005; 105:4416-4423.
11 Andersson S, Fauriat C, Malmberg JA, Ljunggren HG, Malmberg KJ: KIR acquisition probabilities are independent of selfHLA class I ligands and increase with cellular KIR expression. Blood 2009;114:95-104.

12 Cooley S, Trachtenberg E, Bergemann TL, Saeteurn K, Klein J, Le CT, Marsh SG, Guethlein LA, Parham P, Miller JS, Weisdorf DJ: Donors with group b KIR haplotypes improve relapse-free survival after unrelated hematopoietic cell transplantation for acute myelogenous leukemia. Blood 2009;113:726-732.

13 Fauriat C, Andersson S, Bjorklund AT, Carlsten M, Schaffer M, Bjorkstrom NK, Baumann BC, Michaelsson J, Ljunggren HG, Malmberg KJ: Estimation of the size of the alloreactive NK cell repertoire: studies in individuals homozygous for the group a KIR haplotype. J Immunol 2008;181:6010-6019. 
-14 Yawata M, Yawata N, Draghi M, Partheniou F, Little AM, Parham P: MHC class i-specific inhibitory receptors and their ligands structure diverse human NK-cell repertoires toward a balance of missing self-response. Blood 2008;112:2369-2380.

15 Uhrberg M: The KIR gene family: life in the fast lane of evolution. Eur J Immunol 2005; 35:10-15.

16 Purdy AK, Campbell KS: Natural killer cells and cancer: regulation by the killer cell Iglike receptors (KIR). Cancer Biol Ther 2009; 8:2211-2220.

17 Cerwenka A, Lanier LL: NKG2D ligands: unconventional MHC class I-like molecules exploited by viruses and cancer. Tissue Antigens 2003;61:335-343.

$\checkmark 18$ Moretta A, Bottino C, Vitale M, Pende D, Cantoni C, Mingari MC, Biassoni R, Moretta L: Activating receptors and coreceptors involved in human natural killer cell-mediated cytolysis. Annu Rev Immunol 2001;19:197223.

-19 Sivori S, Pende D, Bottino C, Marcenaro E, Pessino A, Biassoni R, Moretta L, Moretta A: $\mathrm{NKp} 46$ is the major triggering receptor involved in the natural cytotoxicity of fresh or cultured human NK cells. Correlation between surface density of NKp46 and natural cytotoxicity against autologous, allogeneic or xenogeneic targeT cells. Eur J Immunol 1999;29:1656-1666.

20 Huenecke S, Zimmermann SY, Kloess S, Esser R, BriNKmann A, Tramsen L, Koenig M, Erben S, Seidl C, Tonn T, Eggert A, Schramm A, Bader P, Klingebiel T, Lehrnbecher T, Passweg JR, Soerensen J, Schwabe D, Koehl U: IL-2-driven regulation of NK cell receptors with regard to the distribution of CD16+ and CD16- subpopulations and in vivo influence after haploidentical NK cell infusion. J Immunother 2010;33:200-210.

-21 Forbes SA, Bindal N, Bamford S, Cole C, Kok CY, Beare D, Jia M, Shepherd R, Leung K, Menzies A, Teague JW, Campbell PJ, Stratton MR, Futreal PA: COSMIC: mining complete cancer genomes in the Catalogue of Somatic Mutations in Cancer. Nucleic Acids Res 2011;39(suppl 1):D945-D950.

-22 Smyth MJ, Dunn GP, Schreiber RD: Cancer immunosurveillance and immunoediting: the roles of immunity in suppressing tumor development and shaping tumor immunogenicity. Adv Immunol 2006;90:1-50.

23 Vesely MD, Kershaw MH, Schreiber RD, Smyth MJ: Natural innate and adaptive immunity to cancer. Annu Rev Immunol 2011;29:235-271.

- 24 Groh V, Bahram S, Bauer S, Herman A, Beauchamp M, Spies T: Cell stress-regulated human major histocompatibility complex class I gene expressed in gastrointestinal epithelium. Proc Natl Acad Sci USA 1996;93: 12445-12450.
25 Yamamoto K, Fujiyama Y, Andoh A, Bamba $\mathrm{T}$, Okabe H: Oxidative stress increases MICA and MICB gene expression in the human colon carcinoma cell line (CACO-2). Biochim Biophys Acta 2001;1526:10-12.

26 Gasser S, Orsulic S, Brown EJ, Raulet DH: The DNA damage pathway regulates innate immune system ligands of the NKG2D receptor. Nature 2005;436:1186-1190.

27 Boissel N, Rea D, Tieng V, Dulphy N, Brun M, Cayuela JM, Rousselot P, Tamouza R, Le Bouteiller P, Mahon FX, Steinle A, Charron D, Dombret H, Toubert A: Bcr/abl oncogene directly controls MHC class I chain-related molecule a expression in chronic myelogenous leukemia. J Immunol 2006; 176:51085116.

28 Wiemann K, Mittrucker HW, Feger U, Welte SA, Yokoyama WM, Spies T, Rammensee HG, Steinle A: Systemic NKG2D down-regulation impairs NK and CD8 T cell responses in vivo. J Immunol 2005; 175:720-729.

29 Oppenheim DE, Roberts SJ, Clarke SL, Filler R, Lewis JM, Tigelaar RE, Girardi M, Hayday AC: Sustained localized expression of ligand for the activating NKG2D receptor impairs natural cytotoxicity in vivo and reduces tumor immunosurveillance. Nat Immunol 2005;6:928-937.

30 Castriconi R, Cantoni C, Della Chiesa M, Vitale M, Marcenaro E, Conte R, Biassoni R, Bottino C, Moretta L, Moretta A: Transforming growth factor $\beta 1$ inhibits expression of NKp30 and NKG2D receptors: consequences for the NK-mediated killing of dendritic cells. Proc Natl Acad Sci USA 2003; 100:4120-4125.

-31 Lee JC, Lee KM, Kim DW, Heo DS: Elevated TGF- $\beta 1$ secretion and down-modulation of NKG2D underlies impaired NK cytotoxicity in cancer patients. J Immunol 2004;172: 7335-7340.

32 Friese MA, Wischhusen J, Wick W, Weiler M, Eisele G, Steinle A, Weller M: Rna interference targeting transforming growth factor- $\beta$ enhances NKG2D-mediated antiglioma immune response, inhibits glioma cell migration and invasiveness, and abrogates tumorigenicity in vivo. Cancer Res 2004;64: 7596-7603.

33 Flavell RA, Sanjabi S, Wrzesinski SH, Licona-Limon P: The polarization of immune cells in the tumour environment by tgfbeta. Nat Rev Immunol 2010;10:554-567.

34 Ghiringhelli F, Menard C, Terme M, Flament C, Taieb J, Chaput N, Puig PE, Novault S, Escudier B, Vivier E, Lecesne A, Robert C, Blay JY, Bernard J, Caillat-Zucman S, Freitas A, Tursz T, Wagner-Ballon O, Capron C, Vainchencker W, Martin F, Zitvogel L: CD4+CD25+ regulatory T cells inhibit natural killer cell functions in a transforming growth factor- $\beta$-dependent manner. J Exp Med 2005;202:1075-1085.
35 Schwinn N, Vokhminova D, Sucker A, Textor S, Striegel S, Moll I, Nausch N, Tuettenberg J, Steinle A, Cerwenka A, Schadendorf $\mathrm{D}$, Paschen A: Interferon-gamma downregulates NKG2D ligand expression and impairs the NKG2D-mediated cytolysis of MHC class i-deficient melanoma by natural killer cells. Int J Cancer 2009;124:1594-1604.

36 Glozak MA, Seto E: Histone deacetylases and cancer. Oncogene 2007;26:5420-5432.

37 Armeanu S, Bitzer M, Lauer UM, Venturelli S, Pathil A, Krusch M, Kaiser S, Jobst J, Smirnow I, Wagner A, Steinle A, Salih HR: Natural killer cell-mediated lysis of hepatoma cells via specific induction of NKG2D ligands by the histone deacetylase inhibitor sodium valproate. Cancer Res 2005;65:63216329.

38 Kato N, Tanaka J, Sugita J, Toubai T, Miura Y, Ibata M, Syono Y, Ota S, Kondo T, Asaka $\mathrm{M}$, Imamura M: Regulation of the expression of MHC class I-related chain A, B (MICA, $\mathrm{MICB})$ via chromatin remodeling and its impact on the susceptibility of leukemic cells to the cytotoxicity of NKG2D-expressing cells. Leukemia 2007;21:2103-2108.

39 Lopez-Soto A, Folgueras AR, Seto E, Gonzalez S: HDAC3 represses the expression of NKG2D ligands ulbps in epithelial tumour cells: potential implications for the immunosurveillance of cancer. Oncogene 2009;28: 2370-2382.

40 Stern-Ginossar N, Elefant N, Zimmermann A, Wolf DG, Saleh N, Biton M, Horwitz E, Prokocimer Z, Prichard M, Hahn G, Goldman-Wohl D, Greenfield C, Yagel S, Hengel $\mathrm{H}$, Altuvia $\mathrm{Y}$, Margalit $\mathrm{H}$, Mandelboim O: Host immune system gene targeting by a viral mirna. Science 2007;317:376-381.

-41 Salih HR, Holdenrieder S, Steinle A: Soluble NKG2D ligands: prevalence, release, and functional impact. Front Biosci 2008;13: 3448-3456.

42 Salih HR, Rammensee HG, Steinle A: Cutting edge: down-regulation of MICA on human tumors by proteolytic shedding. J Immunol 2002;169:4098-4102.

43 Holdenrieder S, Stieber P, Peterfi A, Nagel D, Steinle A, Salih HR: Soluble MICA in malignant diseases. Int J Cancer 2006;118:684687.

44 Kloess S, Huenecke S, Piechulek D, Esser R, Koch J, Brehm C, Soerensen J, Gardlowski T, Brinkmann A, Bader P, Passweg J, Klingebiel T, Schwabe D, Koehl U: IL-2-activated haploidentical NK cells restore NKG2D-mediated NK-cell cytotoxicity in neuroblastoma patients by scavenging of plasma MICA. Eur J Immunol 2010;40:3255-3267.

45 Groh V, Smythe K, Dai Z, Spies T: Fas-ligand-mediated paracrine $\mathrm{T}$ cell regulation by the receptor NKG2D in tumor immunity. Nat Immunol 2006;7:755-762.

46 Vihinen P, Kahari VM: Matrix metalloproteinases in cancer: prognostic markers and therapeutic targets. Int J Cancer 2002;99: 157-166. 
-47 Kaiser BK, Yim D, Chow IT, Gonzalez S, Dai Z, Mann HH, Strong RK, Groh V, Spies T: Disulphide-isomerase-enabled shedding of tumour-associated NKG2D ligands. Nature 2007;447:482-486.

-48 Waldhauer I, Goehlsdorf D, Gieseke F, Weinschenk T, Wittenbrink M, Ludwig A, Stevanovic S, Rammensee HG, Steinle A: Tumor-associated MICA is shed by ADAM proteases. Cancer Res 2008;68:6368-6376.

-49 Kohga K, Takehara T, Tatsumi T, Miyagi T, Ishida H, Ohkawa K, Kanto T, Hiramatsu N, Hayashi N: Anticancer chemotherapy inhibits MHC class I-related chain A ectodomain shedding by downregulating ADAM10 expression in hepatocellular carcinoma. Cancer Res 2009;69:8050-8057.

-50 Liu G, Atteridge CL, Wang X, Lundgren AD, $\mathrm{Wu}$ JD: The membrane type matrix metalloproteinase MMP14 mediates constitutive shedding of MHC class I chain-related molecule a independent of a disintegrin and metalloproteinases. J Immunol 2010;184:33463350.

-51 Ashiru O, Boutet P, Fernandez-Messina L, Aguera-Gonzalez S, Skepper JN, Vales-Gomez M, Reyburn HT: Natural killer cell cytotoxicity is suppressed by exposure to the human NKG2D ligand MICA*008 that is shed by tumor cells in exosomes. Cancer Res 2010;70:481-489.

52 Fernandez-Messina L, Ashiru O, Boutet P, Aguera-Gonzalez S, Skepper JN, Reyburn HT, Vales-Gomez M: Differential mechanisms of shedding of the glycosylphosphatidylinositol (GPI)-anchored NKG2D ligands. J Biol Chem 2010;285:8543-8551.

53 Lodoen MB, Lanier LL: Viral modulation of NK cell immunity. Nat Rev Microbiol 2005; 3:59-69.

-54 Mandelboim O, Lieberman N, Lev M, Paul L, Arnon TI, Bushkin Y, Davis DM, Strominger JL, Yewdell JW, Porgador A: Recognition of haemagglutinins on virus-infected cells by NKp46 activates lysis by human NK cells. Nature 2001;409:1055-1060.

- 55 Jonjic S, Babic M, Polic B, Krmpotic A: Immune evasion of natural killer cells by viruses. Curr Opin Immunol 2008;20:30-38.

56 Koch J, Tampe R: The macromolecular peptide-loading complex in MHC class I-dependent antigen presentation. Cell Mol Life Sci 2006;63:653-662.

57 Cohen GB, Gandhi RT, Davis DM, Mandelboim O, Chen BK, Strominger JL, Baltimore D: The selective downregulation of class I major histocompatibility complex proteins by HIV-1 protects HIV-infected cells from NK cells. Immunity 1999;10:661-671.

58 Falk CS, Mach M, Schendel DJ, Weiss EH, Hilgert I, Hahn G: NK cell activity during human cytomegalovirus infection is dominated by US2-11-mediated HLA class I down-regulation. J Immunol 2002; 169: $3257-3266$
Wilkinson GW, Tomasec P, Stanton RJ, Armstrong M, Prod'homme V, Aicheler R, McSharry BP, Rickards CR, Cochrane D, Llewellyn-Lacey S, Wang EC, Griffin CA, Davison AJ: Modulation of natural killer cells by human cy tomegalovirus. J Clin Virol 2008;41:206-212.

60 Tomasec P, Braud VM, Rickards C, Powell MB, McSharry BP, Gadola S, Cerundolo V, Borysiewicz LK, McMichael AJ, Wilkinson GW: Surface expression of HLA-E, an inhibitor of natural killer cells, enhanced by human cytomegalovirus GPUL40. Science 2000;287:1031.

61 Krmpotic A, Busch DH, Bubic I, Gebhardt F, Hengel H, Hasan M, Scalzo AA, Koszinowski UH, Jonjic S: Mcmv glycoprotein GP40 confers virus resistance to CD8+ T cells and NK cells in vivo. Nat Immunol 2002;3:529535

62 Coscoy L: Immune evasion by Kaposi's sarcoma-associated herpesvirus. Nat Rev Immunol 2007;7:391-401.

-63 Welte SA, Sinzger C, Lutz SZ, Singh-Jasuja H, Sampaio KL, Eknigk U, Rammensee HG, Steinle A: Selective intracellular retention of virally induced NKG2D ligands by the human cytomegalovirus ul16 glycoprotein. Eur J Immunol 2003;33:194-203.

64 Cerboni C, Neri F, Casartelli N, Zingoni A, Cosman D, Rossi P, Santoni A, Doria M: Human immunodeficiency virus $1 \mathrm{NEF}$ protein downmodulates the ligands of the activating receptor NKG2D and inhibits natural killer cell-mediated cytotoxicity. J Gen Virol 2007; 88:242-250.

65 Zheng ZY, Zucker-Franklin D: Apparent ineffectiveness of natural killer cells vis-a-vis retrovirus-infected targets. J Immunol 1992; 148:3679-3685.

66 Poggi A, Carosio R, Spaggiari GM, Fortis C, Tambussi G, Dell'Antonio G, Dal Cin E, Rubartelli A, Zocchi MR: NK cell activation by dendritic cells is dependent on LFA-1-mediated induction of calcium-calmodulin kinase II: inhibition by HIV-1 Tat C-terminal domain. J Immunol 2002;168:95-101.

67 Wills MR, Carmichael AJ, Mynard K, Jin X, Weekes MP, Plachter B, Sissons JG: The human cytotoxic T-lymphocyte (CTL) response to cytomegalovirus is dominated by structural protein pp65: Frequency, specificity, and T-cell receptor usage of pp65-specific CTL. J Virol 1996;70:7569-7579.

-68 Arnon TI, Achdout H, Levi O, Markel G, Saleh N, Katz G, Gazit R, Gonen-Gross T, Hanna J, Nahari E, Porgador A, Honigman A, Plachter B, Mevorach D, Wolf DG, Mandelboim O: Inhibition of the NKp30 activating receptor by pp65 of human cytomegalovirus. Nat Immunol 2005;6:515-523.

69 Stern-Ginossar N, Mandelboim O: An integrated view of the regulation of NKG2D ligands. Immunology 2009;128:1-6.

70 Alcami A, Koszinowski UH: Viral mechanisms of immune evasion. Immunol Today 2000;21:447-455.
Tortorella D, Gewurz BE, Furman $\mathrm{MH}$, Schust DJ, Ploegh HL: Viral subversion of the immune system. Annu Rev Immunol 2000; 18:861-926.

72 Inngjerdingen M, Damaj B, Maghazachi AA: Expression and regulation of chemokine receptors in human natural killer cells. Blood 2001;97:367-375.

73 Slobedman B, Barry PA, Spencer JV, Avdic $\mathrm{S}$, Abendroth A: Virus-encoded homologs of cellular interleukin-10 and their control of host immune function. J Virol 2009;83: 9618-9629.

74 Born TL, Morrison LA, Esteban DJ, VandenBos T, Thebeau LG, Chen N, Spriggs MK, Sims JE, Buller RM: A poxvirus protein that binds to and inactivates IL-18, and inhibits NK cell response. J Immunol 2000;164: 3246-3254.

75 Hayakawa Y, Smyth MJ: Innate immune recognition and suppression of tumors. Adv Cancer Res 2006;95:293-322.

-76 Fehniger TA, Cooper MA, Caligiuri MA: Interleukin-2 and interleukin-15: immunotherapy for cancer. Cytokine Growth Factor Rev 2002;13:169-183.

-77 Ferlazzo G, Pack M, Thomas D, Paludan C Schmid D, Strowig T, Bougras G, Muller WA Moretta L, Munz C: Distinct roles of IL-12 and IL-15 in human natural killer cell activation by dendritic cells from secondary lymphoid organs. Proc Natl Acad Sci USA 2004; 101:16606-16611.

78 Ruggeri L, Capanni M, Urbani E, Perruccio K, Shlomchik WD, Tosti A, Posati S, Rogaia D, Frassoni F, Aversa F, Martelli MF, Velardi A: Effectiveness of donor natural killer cell alloreactivity in mismatched hematopoietic transplants. Science 2002;295:2097-2100.

-79 Melamed R, Bar-YosefS, Shakhar G, Shakhar $\mathrm{K}$, Ben-Eliyahu S: Suppression of natural killer cell activity and promotion of tumor metastasis by ketamine, thiopental, and halothane, but not by propofol: mediating mechanisms and prophylactic measures. Anesth Analg 2003;97:1331-1339.

80 Ljunggren HG, Malmberg KJ: Prospects for the use of NK cells in immunotherapy of human cancer. Nat Rev Immunol 2007;7:329339.

81 Rosenberg SA, Lotze MT, Muul LM, Leitman S, Chang AE, Ettinghausen SE, Matory YL, Skibber JM, Shiloni E, Vetto JT, et al: Observations on the systemic administration of autologous lymphokine-activated killer cells and recombinant interleukin-2 to patients with metastatic cancer. N Engl J Med 1985; 313:1485-1492.

82 Passweg JR, Stern M, Koehl U, Uharek L, Tichelli A: Use of natural killer cells in hematopoetic stem cell transplantation. Bone Marrow Transplant 2005;35:637-643.

83 Passweg JR, Koehl U, Uharek L, Meyer-Monard S, Tichelli A: Natural-killer-cell-based treatment in haematopoietic stem-cell transplantation. Best Pract Res Clin Haematol 2006;19:811-824. 
84 Koehl U, Bochennek K, Zimmermann SY, Lehrnbecher T, Sorensen J, Esser R, Andreas C, Kramm C, Gruttner HP, Falkenberg E, Orth A, Bader P, Schwabe D, Klingebiel T: Immune recovery in children undergoing allogeneic stem cell transplantation: Absolute $\mathrm{CD} 8+\mathrm{CD} 3+$ count reconstitution is associated with survival. Bone Marrow Transplant 2007;39:269-278.

85 Dulphy N, Haas P, Busson M, Belhadj S, Peffault de Latour R, Robin M, Carmagnat $M$, Loiseau P, Tamouza R, Scieux C, Rabian C, Di Santo JP, Charron D, Janin A, Socie G, Toubert A: An unusual CD56(bright) CD16(low) NK cell subset dominates the early posttransplant period following HLAmatched hematopoietic stem cell transplantation. J Immunol 2008;181:2227-2237.

86 Nguyen S, Dhedin N, Vernant JP, Kuentz M, Al Jijakli A, Rouas-Freiss N, Carosella ED, Boudifa A, Debre P, Vieillard V: NK-cell reconstitution after haploidentical hematopoietic stem-cell transplantations: Immaturity of NK cells and inhibitory effect of NKG2A override GvL effect. Blood 2005; 105:41354142.
87 McKenna DH Jr, Sumstad D, Bostrom N, Kadidlo DM, Fautsch S, McNearney S, Dewaard R, McGlave PB, Weisdorf DJ, Wagner JE, McCullough J, Miller JS: Good manufacturing practices production of natural killer cells for immunotherapy: a six-year singleinstitution experience. Transfusion 2007;47: 520-528.

88 Passweg JR, Tichelli A, Meyer-Monard S, Heim D, Stern M, Kuhne T, Favre G, Gratwohl A: Purified donor NK-lymphocyte infusion to consolidate engraftment after haploidentical stem cell transplantation. Leukemia 2004;18:1835-1838.

89 Iyengar R, Handgretinger R, BabarinDorner A, Leimig T, Otto M, Geiger TL, Holladay MS, Houston J, Leung W: Purification of human natural killer cells using a clinicalscale immunomagnetic method. Cytotherapy 2003;5:479-484.

90 Koehl U, Sorensen J, Esser R, Zimmermann S, Gruttner HP, Tonn T, Seidl C, Seifried E, Klingebiel T, Schwabe D: IL-2 activated NK cell immunotherapy of three children after haploidentical stem cell transplantation. Blood Cells Mol Dis 2004;33:261-266.
91 Koehl U, Esser R, Zimmermann S, Tonn T, Kotchetkov R, Bartling T, Sorensen J, Gruttner HP, Bader P, Seifried E, Martin H, Lang P, Passweg JR, Klingebiel T, Schwabe D: Ex vivo expansion of highly purified NK cells for immunotherapy after haploidentical stem cell transplantation in children. Klin Padiatr 2005;217:345-350.

92 Miller JS, Soignier Y, Panoskaltsis-Mortari A, McNearney SA, Yun GH, Fautsch SK, McKenna D, Le C, Defor TE, Burns LJ, Orchard PJ, Blazar BR, Wagner JE, Slungaard A, Weisdorf DJ, Okazaki IJ, McGlave PB: Successful adoptive transfer and in vivo expansion of human haploidentical NK cells in patients with cancer. Blood 2005;105:30513057.

93 Rubnitz JE, Inaba H, Ribeiro RC, Pounds S, Rooney B, Bell T, Pui CH, Leung W: NKaml: A pilot study to determine the safety and feasibility of haploidentical natural killer cell transplantation in childhood acute myeloid leukemia. J Clin Oncol 2010;28:955-959.

94 Raffaghello L, Prigione I, Airoldi I, Camoriano $\mathrm{M}$, Morandi $\mathrm{F}$, Bocca $\mathrm{P}$, Gambini $\mathrm{C}$, Ferrone S, Pistoia V: Mechanisms of immune evasion of human neuroblastoma. Cancer Lett 2005;228:155-161. 